\title{
The Challenges of Having an Infant Participate in the Simulation-based Course: "Examination of a Healthy Infant"
}

\author{
Hanne Storm*
}

Skills Training Centre, Medical Faculty, University of Oslo, Norway

\begin{abstract}
Background: The Skills Training Centre has developed a course where medical students learn to perform a systematic pediatric examination of an infant.

Aim: The aim of this study is to describe the logistical, educational, legal and ethical concerns of this simulationbased course.

Method: During the pediatrics component in the $9^{\text {th }}$ semester, medical students were offered voluntary the opportunity to examine an infant accompanied by an instructor (final year medical student). Afterwards, the instructor and the medical student discussed the medical student's examination technique and communication skills. A questionnaire was used to evaluate the relevance of the course.

Results: 50 per cent of the students passed the course. Logistical challenges were posed by the need to request parents with healthy infants ( 3 months to 1 year) at the child health centre to participate, and to organize the course time. A secretary organized the logistics. The educational challenge was to draw benefit from the individual behavior of infants and mothers. The variation in behavior was used to improve the communication skills of the medical student. There were legal and ethical concerns related to handling the medical student's non-healthy findings on the infants. These findings were dealt with by the pediatrician in charge of the course. The course was evaluated as suitable and relevant. All the parents would recommend this session to other parents at the child health centre.

Conclusion: It is possible to surmount logistical, educational, legal, and ethical concerns in relation to a simulationbased course where an infant is involved. The endorsement of the course indicates that it should continue.
\end{abstract}

Keywords: child health centres, infant, medical students, parents, simulation-based course, student instructor.

\section{INTRODUCTION}

Medical students are currently facing a shift in the teaching paradigm. The increasing amount of medical information and research makes it difficult for medical education to be updated. Patients are often concerned that medical students are "practicing"' on them, because clinical medicine is becoming more focused on patient safety and quality than on bedside teaching and education. One way to approach these challenges is to build up education based on simulation. Simulation is an instructional process that substitutes artificial models, live actors, or virtual reality patients [1] for real patient encounters. The goal of simulation is to reproduce patient diagnosis and treatment in a realistic environment with feedback and assessment from instructors. If the simulation is properly conducted, it can create an ideal educational environment because learning activities can be made predictable, consistent, standardized, safe, and reproducible [2]. Furthermore,

*Address correspondence to this author at the Skills Training Centre, Medical Faculty University of Oslo, Norway; Tel: + 47 90788976;

+47 23074398; Fax: + 47 22546678; E-mail: hanne.storm@medisin.uio.no when using the simulation technology, it is possible to demonstrate multiple patient problems and critical events [2]. For these reasons simulation technology is accepted in medical education. The first model used to teach airway and resuscitative skills was developed 70 years ago [3]. Since that time, more and more simulation models have become available [4-6]. Interestingly, clinical skills benefit from learning through practical training because students tend to remember 90 per cent of what they do but only 10 per cent of what they read [7].

The Skills Training Centre at the University of Oslo's Faculty of Medicine is based on the model of the University of Maastricht, the Netherlands, and only medical students can use it [8]. The Centre consists of six rooms for different training procedures, see Table $\mathbf{1}$. The rooms have different models for training and a computer with internet to connect with multimedia programs or educational films; user instructions for the different models are available. The Centre has established voluntary and mandatory courses. The voluntary courses see Table $\mathbf{2}$, are given by medical student instructors working part time and trained as instructors by university teachers at the Faculty of Medicine. In total there are 9 medical student instructors 
Table 1. The Contents of the Different Rooms at the Skills Training Centre

\begin{tabular}{|l|l|l|}
\hline \multicolumn{2}{|c|}{ Room } & \multicolumn{1}{c|}{ Equipment } \\
\hline \hline 1 & Heart-lung room & $\begin{array}{l}\text { Heart Lung Resuscitation, adult, children and infant models. Intubation models. Electrocardiography. Digi- } \\
\text { tal common stethoscope. }\end{array}$ \\
\hline 2 & Infusion-suture room & Bladder catheterization, infusion, biopsy, and suturing models. Equipment for blood sampling. \\
\hline 3 & Gynaecology and obstetrics room & $\begin{array}{l}\text { Model for palpation of mama with tumour. } \\
\text { Pregnancy model for Leopold's manoeuvre. Model for fetus heart sound. Models for gynaecological exami- } \\
\text { nation with assessors. }\end{array}$ \\
\hline 4 & $\begin{array}{l}\text { Ear-nose-throat, eye, and neurology } \\
\text { room }\end{array}$ & $\begin{array}{l}\text { Models for lumbar puncture, ophthalmoscopy and otoscopy with pathological findings. Tonometry and } \\
\text { audiometry. Ophthalmic glass box. }\end{array}$ \\
\hline 6 & $\begin{array}{l}\text { Thorax, abdomen and microscopy } \\
\text { room }\end{array}$ & \begin{tabular}{l} 
Common microscope (8 headed), models for rectal exploration with prostate pathology and ano-rectoscopy. \\
\hline
\end{tabular} \\
\hline
\end{tabular}

Table 2. Overview of the Different Mandatory and Voluntary Courses Offered at the Skills Training Centre

\begin{tabular}{|c|c|c|c|c|c|}
\hline Courses & $\begin{array}{c}\text { Hours Per } \\
\text { Course }\end{array}$ & $\begin{array}{c}\text { Number of } \\
\text { Courses }\end{array}$ & $\begin{array}{c}\text { Total Number } \\
\text { of Hours }\end{array}$ & $\begin{array}{c}\text { Participants } \\
\text { Per Course }\end{array}$ & $\begin{array}{l}\text { Total Number } \\
\text { of Participants }\end{array}$ \\
\hline Semester 3: Examination of the thorax 1) & 2.5 & 19 & 47.5 & $7-8$ & $133-152$ \\
\hline Semester 4: Examination of the abdomen 1) & 2.5 & 14 & 35 & $7-8$ & $98-112$ \\
\hline Semester 4: Examination of the muscle-skeletal system & 2.5 & 16 & 40 & $10-12$ & $160-192$ \\
\hline Semester 5: Electrocardiography & 2 & 10 & 20 & $8-10$ & $80-100$ \\
\hline Semester 7: Lumbar puncture & 1.5 & 10 & 15 & $8-10$ & $80-100$ \\
\hline Semester 9: Gynaecological examination & 1.5 & 10 & 15 & $8-10$ & $80-100$ \\
\hline Semester 9: Examination of infants & 1 & 80 & 80 & 1 & 80 \\
\hline Semester 10: Heart Lung Resuscitation & 1.5 & 8 & 12 & 8 & 64 \\
\hline Semester 12: Examination of the muscle-skeletal system & 2.5 & 16 & 40 & $10-12$ & $160-192$ \\
\hline Total & & 183 & 304.5 & & 935-1092 \\
\hline
\end{tabular}

1) Mandatory courses

working 8 hours per week. In addition, the head of the Skills Training Centre, a university teacher, is responsible for the mandatory lectures, see Table $\mathbf{2}$. Before the introduction of the Objective Structured Clinical Examination (OSCE), about 1000 medical students participated in the voluntary courses established at the Skills Training Centre each semester (there are two semesters a year). After the introduction of the OSCE the number of medical students who wanted to have these courses nearly doubled. Several medical students had never handled an infant before commencing the pediatrics component. The simulation- based course "Examination of the healthy infant" was established to teach the student skills related to handling an infant using medical examination techniques and communication skills, see Table 3 . The clinical background and when to perform the different examinations were taught at other stages of the pediatric studies.

The challenges of including an infant in this course are discussed in relation to the logistical, educational, legal and ethical concerns. Furthermore, an evaluation is presented of the relevance of the course, of whether the medical student instructors represented an adequate re- 
source for carrying out these courses, and if the parents involved were satisfied with the situation when their infant was examined.

\section{METHODS}

Between 90 and 110 medical students participate in the pediatrics and gynaecology component in the $5^{\text {th }}$ year of their studies. Half the group focuses on pediatrics for a number of weeks while the other half focuses on gynaecology. The simulation-based course "Examination of a healthy infant" was offered on a voluntary basis to 45 medical students in the weeks devoted to pediatrics. The examination of the infant lasted for 30 minutes, and was followed by a 15-minute discussion with an instructor (final year medical student). The instructor and the medical student discussed the medical student's examination technique and communication skills. The course included: observation, taking the case history focusing on communication, examination of the head, the eyes, the mouth, the ears, the neck, the chest, the abdomen, the pulses, the feet, the spine, and the genitalia, see Table $\mathbf{3}$ and Fig. (1), and was quality assured by the pediatrician in charge of teaching medical students at the University of Oslo. It was assumed that the clinical knowledge of the medical students

Table 3. The "Examination of a healthy infant" course manual is quality assured by a pediatrician employed at the university. The course is held at the Skills Training Centre

\section{PEDIATRIC EXAMINATION - THE SKILLS TRAINING CENTRE}

Observation:

- Carefully observe the child's behaviour when taking the case history and during the examination.

- Make a mental note of what milestones and developmental stages the child should have passed, and what you expect to observe throughout the consultation.

Taking the case history with focus on how to communicate with parents and infants:

Reason for seeking medical attention? (Addressing the acute problem)

Other issues which are often addressed during a pediatric consultation:

Pregnancy:

- First pregnancy? Special problems?

- Infections? Medication? Smoking? Alcohol? Folic acid?

Birth:

- Term? Weight? Length? Head circumference?

- Crying? Colour? Resuscitation? (Apgar score), Yellow?

- How long in hospital? (Prolonged stay? Why?)

The child's health:

- Family/social situation

- Hereditary diseases in the family, other diseases in the family

- Has he/she been ill? Been to hospital? Seen a doctor?

- Natural functions: Sleeping? Eating? Breastfeeding/Baby formula? Urinating? Bowel motions?

- Allergies/food intolerance?

- Medication? (Now or earlier). Immunization: Has he/she been following the regular programme at the child health centre. Why not?

- Does anyone smoke at home? Pets?

\section{Examination:}

- Head: shape

- Eyes: Red reflex, squinting? Eye movement.

- Mouth: Normal uvula. WAIT TO THE END. (NB! Screw stick position)

- Ears: Normal membrane? WAIT TO THE END. (NB! Screw stick position.)

- Neck: Lymph nodes? Other tumours? Movement.

- Chest: Listen to heart and lungs

- Abdomen: Bowel sounds? Check for enlarged liver, spleen, kidneys.

- Pulses: Femoral and brachial: compare left and right side

- Feet: Can the foot be brought to a normal position? Grip reflex?

- Spine: Pits or other abnormalities? Myelomeningocele?

- Boys: Testis/hypospadias? Girls: Vaginal synechia? 


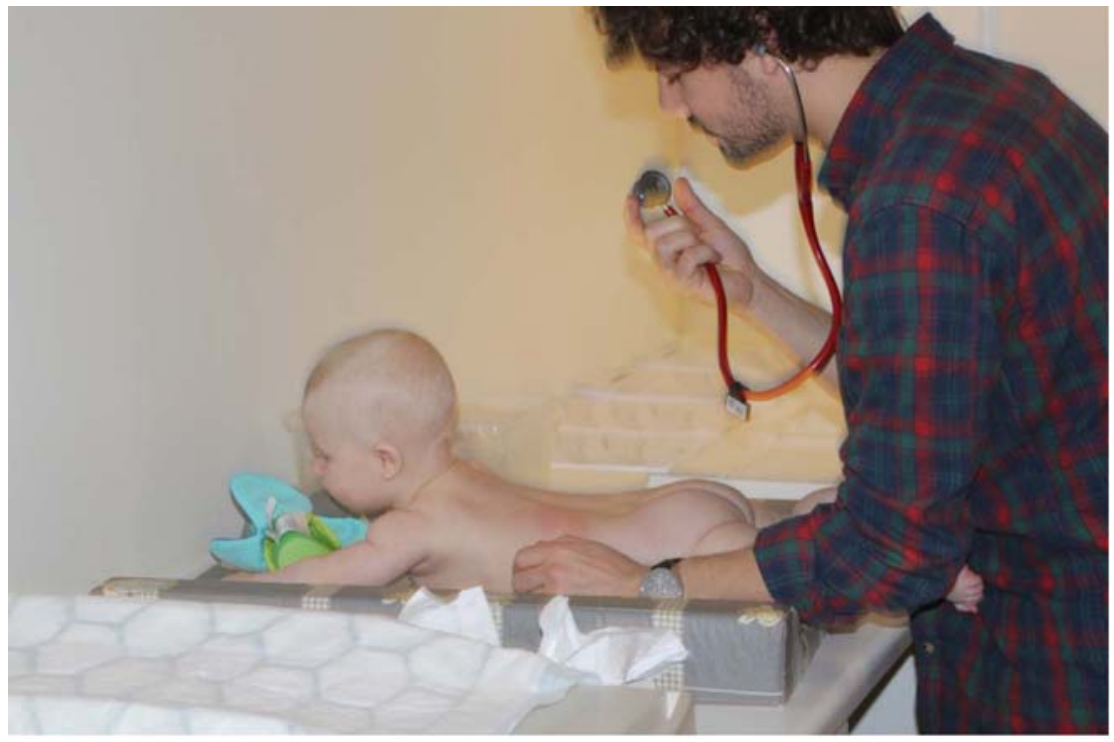

Fig. (1). The examination situation (permission from both the medical student and the mother of the infant to publish the picture).

Table 4. Evaluation form from the Student Section, Faculty of Medicine, UIO
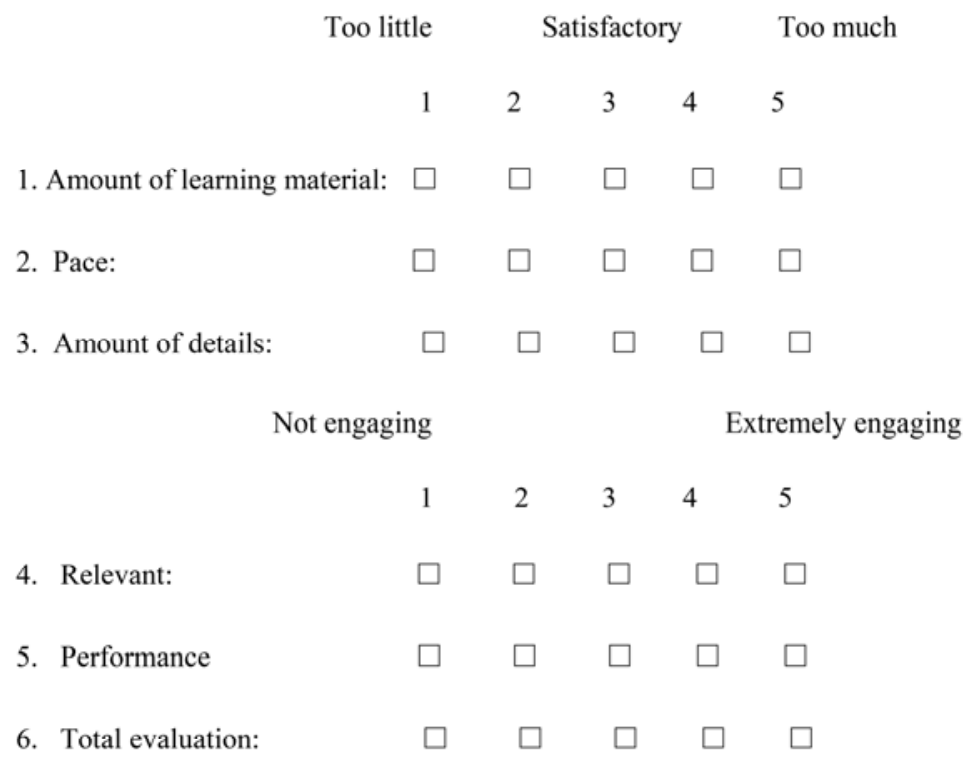

Other comments:

and when to perform the different examinations had been learned elsewhere. Parents with healthy infants aged from 3 months to 1 year from child health centres in the neighbourhood were asked if they wanted to come to the Skills Training Centre and allow their infant to be examined by a medical student. The parents received a children's book as a gift after the lecture. The evaluation questionnaire was developed by the Student Section of UiO's Faculty of Medicine, and was used to evaluate the pediatrics course after participation, see Table 4. The questionnaire is simple and informative, and shows how the medical students evaluated the relevance of the course. Furthermore, the medical students were asked if they had examined an infant previously, and if they had completed their mandatory training at the child health centres. In addition, the medical students were asked if the course was useful for improving their skills in communication and examination technique, and to evaluate the student instructor. The questionnaire has a scale of from 1 (very poor) to 10 (very good), and was answered immediately after the course. The mothers were asked if they would recommend the session to other mothers at the child health centre.

\section{RESULTS}

50 per cent of the medical students completed this voluntary course. Logistical challenges were posed by the need to request mothers with healthy infants ( 3 months to 
1 year) at the child health centres to attend, and to coordinate the schedules of the mothers, medical students and instructors vis-à-vis the time of the course. The child health centre asked the parents if they wanted to participate in the course when the parent joined the maternity group. To motivate the staff at the child health centre to present the course for the parents, the instructors went to the child health centres twice a year with a box of chocolates. A secretary at the Faculty of Medicine organized the mothers, medical students and instructor's schedules so that their schedules concurred with the time of the course. The parents received a children's book as a gift after the lecture. The educational challenge was to derive benefit from the differing behaviour of infants and mothers, and to teach the medical students communication skills based on the individual behaviour. The medical students learned from these individual differences during the feedback in the discussion with the instructor after the lecture. There were legal and ethical concerns related to handling the medical student's non-healthy findings on the infant, if any. Such findings were dealt with by the university employed pediatrician who was in charge of the course. The pediatrician was contacted if non-healthy findings were discovered, and he/she followed up these findings.

Results of evaluation of the Pediatric course by the medical students showed that the course was validated as suitable regarding the amount of learning, pace and degree of detail, see Table 5 . The course was regarded as relevant, and the performance and total validation were satisfactory, see Table $\mathbf{5}$. Seventy-four percent of the participating students had examined an infant prior to the training. Thirty-seven percent had already completed their mandatory training at the child health centre. All students were in favour of continuing this simulation-based training opportunity. The usefulness of the session in relation to improvement in communication skills and examination technique was rated as $7.7(\mathrm{SD}=2.0)$ and $7.6(\mathrm{SD}=1.8)$, respectively. The students rated the instructors at 8.5 $(\mathrm{SD}=1.5)$ in communication skills and at $8.4(\mathrm{SD}=1.2)$ in examination technique. All the parents would recommend this session to other parents at the child health centre.

\section{DISCUSSION}

About fifty percent of the medical students participated in this voluntary course. The logistical, educational, legal and ethical challenges of the course in which medical students learn how to perform a systematic pediatric examination of a healthy infant were solved in a satisfactory manner. The organization of the simulation-based course, "Examination of a healthy infant", faces some challenges because it is time-consuming and requires the involvement of pediatricians, child health centres, parents, infants, instructors (final year medical students), and a secretary. In spite of these challenges, the endorsement of the course indicates that it should continue. The medical students found the course appropriate in relation to the quantitative content, pace, and degree of detail. In addition, the students found the course relevant regarding the amount of learning and the accuracy in performance. The total validation was satisfactory. Twenty six per cent of the students had not examined any infants prior to this course. The instructors, who had been taught by the pediatrician in charge of the course, performed satisfactorily when teaching the medical students. The pediatrician had quality assured the course manual. This indicates that using medical student instructors is cost effective when teaching medical students, and has a potential when establishing similar or other courses. All the parents would recommend this session to other parents at the child health centre. This test was performed before the OSCE was established as part of the pediatrics component at the Faculty of Medicine (UiO). After the OSCE was established, the number of medical students who wanted to participate in this voluntary course increased to about 80 per cent.

Simulation is the replacement of real patient encounters with standardized patients, either living or models, or with technologies that replicate the clinical scenario. These technologies may be simple, for example screenbased video game-type simulations or more practical simulations such as fiber-optic bronchoscope, including chest tube insertion and intubation etc., and full environment simulation (FES) using high-fidelity mannequin simulators. Most of the simulation work in general pediatrics has been focused on neonatal resuscitation. For example Halamek et al. developed a neonatal resuscitation programme in the mid-1990s [9]. Simulation-based education for medical students within pediatrics has a higher potential than simply being used for neonatal resuscitation. It can be used as in the simulation-based course "Examination of a healthy infant". Using an infant as a live standardized patient has not been reported in the literature as a way to train medical students examination skills. The ability to provide immediate directed feedback is the main advantage of simulation. Immediate feedback is typically lacking in the clinical setting when time is limited and the medical students do not want to disturb the patient more than absolutely necessary. The greatest challenge for simulation education is the learner-dependent situation, as it requires full participation and engagement by the teachers [2]. In many countries medical licensing boards and specialty boards require some form of continuing medical education (CME ). When establishing "The examination of a healthy infant" course it was thought that different procedures in the clinical setting would be repeated and taught during the pediatrics component.

For medical students the heart lung resuscitation courses are repeated several times on a voluntary basis in the course of medical studies at UiO. Other courses may benefit from repetition as well. To increase patient safety it would also be possible to establish a minimum of per-

Table 5. Results of Evaluation of the Pediatrics Course by the Medical Students

\begin{tabular}{|c|c|c|c|c|c|}
\hline Amount of Learning Material: & Pace: & Amount of Details: & Relevant: & Performance & Total Evaluation: \\
\hline \hline $3.05+/-0.3$ & $3.05+/-0.3$ & $3.1+/-0.5$ & $4.65+/-0.7$ & $4.65+/-0.7$ & $4.85+/-0.5$ \\
\hline
\end{tabular}


formance criteria on different topics before the students are allowed to practice on patients.

\section{CONCLUSION}

The simulation-based course," Examination of a healthy infant", faces some challenges regarding the logistical, educational and ethical legal aspects. It is timeconsuming and requires the involvement of a pediatrician, child health centres, parents, infants, instructors, and a secretary. In spite of these challenges, the endorsement of the course indicates that it should continue. Involving an infant in a pediatrics course can also be recommended for medical faculties at other universities.

\section{REFERENCES}

[1] Gaba D. The future vision of simulation in health care. Qual Saf Health Care 2004; 13 (suppl 1): i2-i10.

[2] Okuda Y, Bryson EO, DeMaria S, et al. The utility of simulation in medical education: What is evidence? Mt Sinai J Med 2009; 76: 330-43.
[3] Grenvik A, Schaefer J. From Resusci-Anne to Sim-Man: the evolution of simulators in medicine. Crit Care Med 2004; 32(suppl): S56-S57.

[4] Abrahamson S, Denson JS, Wolf RM. Effectiveness of a simulator in training anesthesiology residents. J Med Educ 1969; 44: 515-19.

[5] Cooper JB, Taqueti VR. A brief history of the development of mannequin simulators for clinical education and training. Qual Saf Health Care 2004; 13(suppl 1): i11-i18.

[6] Marsch S. Team oriented medical simulation. In: Hensen LC, Lee AC, eds. Simulators in Anesthesiology Education. New York, NY: Plenum Press 1998; pp. 51-5.

[7] Croley WC, Rothenberg DM. Education of trainees in the intensive care unit. Crit Care Med 2007; 35(suppl): S117-S121

[8] Visser K, Prince KJ, Scherpbier AJ, Van der Vleuten CP, Verwijnen GM. Students can be full partners in designing their education. A quality assessment of skills training. Acad Med 1997; 72(12): 1034-5.

[9] Halamek LP, Kaegi DM, Gaba DM, et al. Time for a new paradigm in pediatric medical education: teaching neonatal resuscitation in simulated delivering room environment. Pediatrics 2000; 106: E45.

(C) Hanne Storm; Licensee Bentham Open.

This is an open access article licensed under the terms of the Creative Commons Attribution Non-Commercial License (http://creativecommons.org/licenses/by-nc/3.0/) which permits unrestricted, non-commercial use, distribution and reproduction in any medium, provided the work is properly cited. 